\title{
IMPROVED PUNCH FORCEPS FOR TANGENTIAL AND EXTRALIMBAL SCLERECTOMY IN CHRONIC GLAUCOMA
}

BY

\author{
S. Holth
}

Christiania, Norway

A YEAR ago I made two improvements in my punch forceps with $1 \mathrm{~mm}$. blade.

In the pattern of 1920 (Brit. Jl. of Ophthal., Fig. 5, p. 547, 1921) the upper surface of the male blade was straight so that the sclera might slip and cause the sclerectomy to be only $1.5 \mathrm{~mm}$. in length instead of $3 \mathrm{~mm}$., which is always necessary. The instrument,

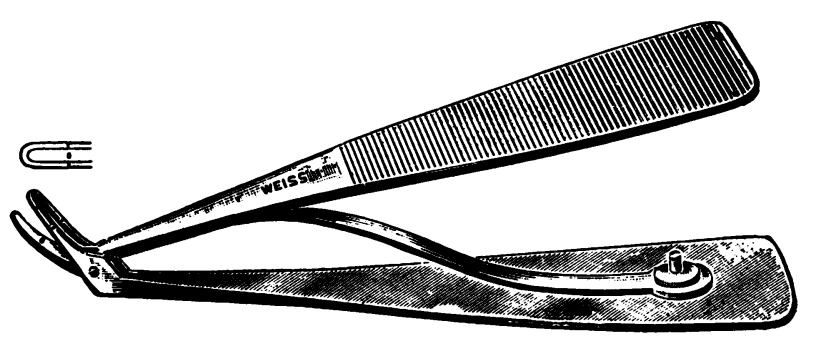

in that case had to be re-introduced in order to make a supplementary sclerectomy of $1.5 \mathrm{~mm}$. In the improved pattern (see the figure) the upper surface of the male blade is made concave so that the sclera cannot slip out and a piece of sclera 1 by $3 \mathrm{~mm}$. is immediately cut out.

A black point is marked on the upper surface of the male blade $4 \mathrm{~mm}$. from the end, and, at the suggestion of my friend $\mathrm{Mr}$. Mayou, two transverse ridges are made on the upper surface of the female blade, also $4 \mathrm{~mm}$. from the end. The instrument is introduced until these marks are $1 \mathrm{~mm}$. outside the median angle of the keratome incision; the resulting sclerectomy will then be . $3 \mathrm{~mm}$. in length.

The operation has now (from the spring of 1920 until the end of December, 1923) been performed here in Christiania in more than 200 cases of chronic glaucoma. Atropin is applied on the following day in order to prevent the formation of posterior synechiae. The lowering of the ocular pressure is good as in the other forms of sclerectomy, and, so far, no case of late infection has been observed. 